\title{
Quality Traps in Localized Competition
}

\author{
Partha Gangopadhyay, Mustafa A. Rahman \& Nasser Elkanj \\ CInIS, University of Western Sydney, Locked Bag 1797, NSW 1797, Australia
}

Received: June 20, 2011

Accepted: September 5, 2011

doi:10.5539/mas.v5n5p3

\begin{abstract}
A wide spectrum of technologies, producing a vast array of product qualities, coexists in modern markets today. Many of these markets are also characterised by what is commonly known as localized competition that refers to a special industrial structure in which different firms compete directly with different groups of rivals. We explore the endogenous choice of product quality in localized competition such that the choice of product quality by a seller has effects only on those rivals who share the common market segment. In the proposed model multiple equilibria may occur and the present analysis may be seen as a rationalization for the idea that a market segment may become trapped in a "low-quality" equilibrium. In the presence of multiple equilibria and the quality trap, the industrial policy may have a welfare-enhancing role in coordinating expectations. We then extend the model to highlight the conditions that can preclude the possibility of the quality trap in localised competition.
\end{abstract}

JEL Classification: F1; H4

Keywords: Endogenous product quality, Multiple equilibria, Stability, Quality trap, Separatrix

\section{Introduction}

In recent years high-tech products have assumed paramount importance in the prosperity of nations and the quality of life for millions. Motor vehicles, health products and computers are among a wide range of products that have gone high-tech. The quality of a product is captured by a vector of specific characteristics (see Shaked and Sutton, 1982).There are three major assumptions to represent product quality by product characteristics: first, every characteristic has a nonnegative marginal utility or return to a consumer. Secondly, the consumption technology relating characteristics to goods is linear. Finally, consumer's utility is independent of the distribution of characteristics among products. The quality of products, captured by their characteristics, is ever-changing as new products driven by new technologies regularly burst into the scene. There are a few global hubs where these products are developed, which gradually spread to other parts of the world. Thus, at a point in time, there exists a vast array of technologies that can produce similar products, however, with varying degrees of product quality examples abound in medical products and automobiles that typically range from the primitive to state-of-the-art products. High-tech markets are also seemingly characterised by what is commonly known as localized competition: localized competition refers to a special industry in which different firms compete directly with different groups of rivals. As a result, the importance of product quality that a seller chooses has effects only on those rivals who share the common market segment. The degree of rivalry is much less intense, or even non-existent, between segments, or localities. The goal of this paper is to blend issues of product quality and localized competition to examine the incentives of rival firms to adapt their technologies which, in turn, determine their product quality. From the proposed model we will derive and characterize an equilibrium product quality in a localized duopoly. It is instructive to note that the equilibrium in a localized duopoly can significantly influence the quality of life of millions.

The quality of such products is patently multi-dimensional and, hence, poses a serious problem for modelling of quality. Early papers by Gabszewicz and Thisse $(1979,1980)$ and Shaked and Sutton (1982) developed models to determine what the levels of qualities are in an industry and the number of different quality brands that are produced in an industry with free entry and exit. It is also examined whether there is any causal relationship between the degree of monopoly power of a firm and its choice of product quality (see Schmalensee, 1979). Early papers by Kleiman and Ophir (1966) and Levhari and Srinivasan (1969) argue that firms with monopoly power have incentives to produce goods with lower qualities. In other words, the monopolist adopts inferior product characteristics like lower durability and fewer features etc.. However, Swan $(1970,1971)$ establishes the counter-intuitive result that there is no causal relationship between monopoly power and quality. The Swan's independence result has triggered a number of papers analysing the independence result (see Kihlstrom and Levhari, 1977). Since the quality of a product is not often readily recognized by consumers and since producers 
typically have more information about their product qualities, a number of papers also focus on the problem of asymmetric information and signalling issues (see Wolinsky, 1983). In recent work, authors have extended the choice of quality to a wider field of research as examples Gratti (2007), Acemoglu (2003), Acemoglo et el. (2001), Berentsen and Rocheteau, (2004), North (2005), Djankov et el. (2002).

As many of modern markets seemingly have characteristics of localized competition, different firms compete directly with different groups of rivals (see Scherer, 1990). In such markets different firms have different private information about their rivals' past actions. This usually results in market segmentation. In the absence of an information exchange mechanism firms cannot observe the past actions of all firms. Communication, hence, becomes a serious problem in these markets. Early models of Hotelling (1929), Chamberlin (1933) and Kaldor (1935) highlighted the problems of localization of competition (see Anderson et. al, 1992 for details). Schmalensee (1985) marshals evidence that morning breakfast cereal industry is characterized by localized competition. Feenstra and Levinsohn (1995) offer econometric evidence of localized competition in the car market. Scherer (1990) discusses interesting antitrust issues in markets with localized competition. Papers by Stigler (1964) and Green and Porter (1984) highlight the problem of imperfect public information with uncertain demand functions, even in non-localized markets. Game theoretic models also examine serious difficulties in homing on equilibrium when agents play repeated games with private information (Ben-Porath and Kahneman, 1996; Kandori and Matsushima 1994). The communication problem can create enormous difficulties in such markets for two sets of reasons: first and foremost, a collusive arrangement cannot be sustained in such markets due to this communication problem. Secondly, such markets can be beset with non-equilibrium behaviours as firms may fail to reach a full-information Nash equilibrium.

The main purpose of the current paper is two-fold: first, we develop a simple model to explain how a localized duopoly may be beset with multiple equilibria and a quality trap that may prevent the equilibrium quality to reach a desirable level in a duopolistic segment. Secondly, we explore conditions that will ensure a unique equilibrium quality and investigate ramifications of the stability properties of the unique equilibrium. Thus, we examine conditions under which the quality trap disappears. The plan of the paper is the following: we present the prototype model in Section 2 present a discussion of results in Section 3, extend the model in Section 4 and conclude in Section 5.

\section{The Model}

We consider a localized market, or market segment, that has duopolists (hereafter sellers) selling a good to a large number of buyers. The following results can be easily extended to an oligopoly with a finite number of sellers, so our results will hold for an oligopoly. The market segment is captured by a simple sequential game: in Stage I sellers choose the product price $\mathrm{P}$ that is treated as an exogenous variable. The idea behind the exogenous price and its robustness has been expounded in Schmalensee (1992). At Stage II sellers choose the product quality while the choice of product quality impinges on individual demand functions in Stage II of the game. In other words, in Stage II these sellers engage in quality competition in the product market to capture the largest possible market shares - given the price of their product chosen in Stage I. The proposed duopoly is localized in the sense that these duopolists directly compete against each other in the specific market segment though a large number of other firms/players are active in other segments. Localization implies that firms operating in different segments do not directly compete with each other (see Schmalensee, 1985). However, there is a possibility of indirect linkages between segments and our paper will offer a new type of indirect linkage between a specific market segment and the overall market, which will drive the main results of the paper. We will propose a possible linkage between a segment and the entire industry in terms of the cost function of a duopolist, which will be introduced shortly. We now look at the necessary ingredients of our analysis.

Stage I: Duopolists have already set a common price $\mathrm{P}$ and knows $\mathrm{Q}$ is the total demand in the market segment they compete.

Stage II: Duopolists choose the product quality to determine their individual shares

The segmented duopoly is characterised by the following assumptions:

Assumption 1: The price in the market segment confronting the duopolists is exogenously set in Stage I and called P. The quantity demanded at $\mathrm{P}$ is $\mathrm{Q}$ and $\mathrm{K}_{\mathrm{i}}$ is the quality of product of duopolist/seller i. Q may be presumed to be arising from a random utility model. $\mathrm{K}_{\mathrm{i}} \geq 0$ and the lowest quality is represented by $\mathrm{K}_{\mathrm{i}}=0$ and the larger the value of $\mathrm{K}_{\mathrm{i}}$ the larger is the quality of the product of duopolist $\mathrm{i}$.

Assumption 2: At price $\mathrm{P}$ the quantity demanded is $\mathrm{Q}$ and the individual market share of duopolist $\mathrm{i}, \mathrm{Q}_{\mathrm{i}}$, is determined by the relative quality $\mathrm{K}_{\mathrm{i}}$ of its product by the following equation: 


$$
\begin{gathered}
\mathrm{Q}_{\mathrm{i}}=\mathrm{Q}\left[\mathrm{K}_{\mathrm{i}} /\left(\mathrm{K}_{\mathrm{i}}+\mathrm{K}_{\mathrm{j}}\right)\right] \\
\mathrm{Q}_{\mathrm{i}}=\mathrm{Q} / 2 \text { for } \mathrm{K}_{\mathrm{i}}=\mathrm{K}_{\mathrm{j}}=0
\end{gathered}
$$

The market share function $\left[\mathrm{K}_{\mathrm{i}} /\left(\mathrm{K}_{\mathrm{i}}+\mathrm{K}_{\mathrm{j}}\right)\right]$ is widely applied in industrial economics as in the context of advertising and endogenous sunk costs investment (Schmalensee, 1972; 1992), and also in various other contexts such as economics of contest, rent-seeking and conflicts. The specific functional form (1a) was aximatised in an early work of Luce (1959) and extended in Skaperdas (1996). Note that $K_{i}$ and $K_{j}$ are the quality choices of duopolist $i$ and duopolist $\mathrm{j}$ in a segment, whereas there exists a vast array of heterogeneous product qualities and associated technologies in the entire industry/market. The linkage between a segment and the entire industry/market is postulated in the following fashion:

Assumption 3: The cost function of the $\mathrm{i}_{\text {th }}$ seller is $\mathrm{C}_{\mathrm{i}}$ :

$$
\mathrm{C}_{\mathrm{i}}=\mathrm{C}_{0}+\mathrm{h}\left(\mathrm{K}_{\mathrm{i}}\right)\left(\mathrm{K}_{\mathrm{i}}-\mathrm{K}^{*}\right)
$$

$\mathrm{C}_{0}$ is the constant average /marginal cost of producing the average product quality $\mathrm{K} *$ that prevails in the market. The average cost goes up (down) as the seller produces product of a higher (lower) product quality by the function $\mathrm{h}\left(\mathrm{K}_{\mathrm{i}}\right)$. Note that the average cost of production of a product quality above (below) the average quality $\mathrm{K}^{*}$ is greater (smaller) than $\mathrm{C}_{0}$. For the sake of simplifying calculations we make the following assumption about $\mathrm{h}\left(\mathrm{K}_{\mathrm{i}}\right)$, which we will generalise later:

Assumption 4: For seller i there is a fixed cost, $\mathrm{L}$, of buying a product quality, or relevant technology, from the global market and the function $\mathrm{h}\left(\mathrm{K}_{\mathrm{i}}\right)$ is given as

$$
\mathrm{h}\left(\mathrm{K}_{\mathrm{i}}\right)=\mathrm{K}_{\mathrm{i}}
$$

From the above assumptions the profit function of seller $\mathrm{i}, \Pi_{\mathrm{i}}$, can be written as

$$
\begin{aligned}
& \Pi_{\mathrm{i}}=\left(\mathrm{P}-\mathrm{C}_{\mathrm{i}}\right)\left[\mathrm{Q}\left[\mathrm{K}_{\mathrm{i}} /\left(\mathrm{K}_{\mathrm{i}}+\mathrm{K}_{\mathrm{j}}\right)\right]-\right. \\
= & {\left[\mathrm{P}-\mathrm{K}_{\mathrm{i}}^{2}+\mathrm{K}^{*} \mathrm{~K}_{\mathrm{i}}-\mathrm{C}_{0}\right] \mathrm{Q}\left[\mathrm{K}_{\mathrm{i}} /\left(\mathrm{K}_{\mathrm{i}}+\mathrm{K}_{\mathrm{j}}\right)\right]-\mathrm{L} }
\end{aligned}
$$

The first order condition to maximise profits is given by

$$
\left[\mathrm{P}-\mathrm{K}_{\mathrm{i}}^{2}+\mathrm{K} * \mathrm{~K}_{\mathrm{i}}-\mathrm{C}_{0}\right]\left[\mathrm{K}_{\mathrm{i}} /\left(\mathrm{K}_{\mathrm{i}}+\mathrm{K}_{\mathrm{j}}\right)\right]=\left[\mathrm{P}-3 \mathrm{~K}_{\mathrm{i}}^{2}+2 \mathrm{~K} * \mathrm{~K}_{\mathrm{i}}-\mathrm{C}_{0}\right]
$$

Assumption 5: We only consider and, hence, assume a symmetric Nash equilibrium in the segmented duopoly and hence

$$
\mathrm{K}_{\mathrm{i}}=\mathrm{K}_{\mathrm{j}}=\mathrm{K}
$$

Substituting (2b) into (2a) gives us the first order condition as

$$
2 \mathrm{~K}=\mathrm{K}\left[\mathrm{P}-\mathrm{K}^{2}+\mathrm{K} * \mathrm{~K}-\mathrm{C}_{0}\right] /\left[\mathrm{P}-3 \mathrm{~K}^{2}+2 \mathrm{~K} * \mathrm{~K}-\mathrm{C}_{0}\right]
$$

Expressing the function $\Gamma$ as

$$
\Gamma(\mathrm{K})=\left[\mathrm{P}-\mathrm{K}^{2}+\mathrm{K} * \mathrm{~K}-\mathrm{C}_{0}\right] /\left[\mathrm{P}-3 \mathrm{~K}^{2}+2 \mathrm{~K} * \mathrm{~K}-\mathrm{C}_{0}\right]
$$

We derive the equilibrium schedule in the segmented duopoly as

$$
\mathrm{K}[2-\Gamma(\mathrm{K})]=0
$$

Now we can observe the first set of results from the simple model:

Proposition 1: The equilibrium schedule (3a) shows that there exist two equilibrium product qualities in the segmented duopoly:

$$
\begin{gathered}
\mathrm{K}^{\mathrm{EE}}=0 \\
\mathrm{~K}^{\mathrm{E}}=0.3 \mathrm{~K}^{*+}\left[\mathrm{Sqrt}\left\{0.09 \mathrm{~K}^{* 2}+.2\left(\mathrm{P}-\mathrm{C}_{0}\right)\right\}\right]>0
\end{gathered}
$$

Note that Sqrt represents the square root operator.

Proof: The first equilibrium $\mathrm{K}^{\mathrm{EE}}$ is trivially true. Setting $2-\Gamma(\mathrm{K})=0$ gives us the following quadratic equation as the equilibrium condition:

$$
5 \mathrm{~K}^{2}-3 \mathrm{~K} * \mathrm{~K}+\left(\mathrm{C}_{0}-\mathrm{P}\right)=0
$$

Note that $\left(3 \mathrm{c}^{\prime}\right)$ has two roots and the smaller root is negative since $\left(\mathrm{C}_{0}-\mathrm{P}\right)<0$ and the larger root is positive and given by equation (3c). QED.

Observation 1: The equilibrium $\mathrm{K}^{\mathrm{E}}$ is inherently unstable while $\mathrm{K}^{\mathrm{EE}}$ is stable.

Proof: It can be seen from the second order condition that the second order condition holds for values of $\mathrm{K}$ such that $\mathrm{K}>\left\{\mathrm{K}^{*} / 3\right\}$. Since $\mathrm{K}^{\mathrm{E}}>\left\{\mathrm{K}^{*} / 3\right\}$, at $\mathrm{K}^{\mathrm{E}}$ both the first and the second order conditions for maximising profits 
hold. Note that the equilibrium condition, or schedule ( $\left.3 c^{\prime}\right)$, can be re-written as a fixed point problem (3d). It is obvious from (3d) that $\mathrm{K}^{\mathrm{E}}$ is stable provided $\Phi^{\prime}\left(\mathrm{K}^{\mathrm{E}}\right)<1$. However, substitution of $\mathrm{K}^{\mathrm{E}}$ into $\Phi^{\prime}\left(\mathrm{K}^{\mathrm{E}}\right)$ violates the stability condition. QED.

Note that the equilibrium schedule $[2-\Gamma(K)=0]$ can be re-written as $(3 \mathrm{~d})$ and see Diagram 1 to confirm $(3 \mathrm{~d})$ :

$$
\mathrm{K}=\mathrm{K}\left[5 \mathrm{~K}^{2}+\mathrm{C}_{0}-\mathrm{P}\right] /\left[3 \mathrm{~K}^{*}\right]=\Phi(\mathrm{K})
$$

\section{Discussion}

The proposed model of quality competition in a segmented duopoly seems to touch upon a number of interesting properties of the proposed duopoly equilibrium. From Diagram 1 we can establish the following. First, there exist multiple Nash equilibria: by construction, one is a high-product quality-equilibrium $\left(\mathrm{K}^{\mathrm{E}}\right)$ and the other represents a low-product quality-equilibrium $\left(\mathrm{K}^{\mathrm{EE}}\right)$. We find that the equilibrium product quality $\mathrm{K}^{\mathrm{E}}$, Pareto-dominant equilibrium, is always unstable and the inferior equilibrium (product quality) $\mathrm{K}^{\mathrm{EE}}$ is stable. If the initial choice of product quality lies in the interval $\left[0, \mathrm{~K}^{\mathrm{E}}\right]$, the dynamics of competition induces the duopolists to adopt the worst possible quality $\mathrm{K}^{\mathrm{EE}}$. If the initial product quality is greater than a critical value $\mathrm{K}^{\mathrm{E}}$, then the dynamics of the system takes the system to the adoption of the best product quality available in the entire industry. Thus the unstable equilibrium $\mathrm{K}^{\mathrm{E}}$ acts as a trap: actual $\mathrm{K}$, or expectations, must lie beyond $\mathrm{K}^{\mathrm{E}}-$ otherwise the system is doomed to get stuck with the worst product quality, or technology.

We thereby establish the existence and convergence properties of equilibrium product quality in a segmented duopoly with two observations: first, the state space of the localized duopoly is divided by separatrix that is driven by the prevailing average product quality in the entire market. The higher the average product quality the larger is the value of this separatrix. This separatrix divides the state space into stable and unstable zones in the context of choice of product quality. If the historical product quality in a duopoly is less than the critical value $\left(\mathrm{K}^{\mathrm{E}}\right)$, then the system converges to the inferior product quality $\left(\mathrm{K}^{\mathrm{EE}}\right)$ as an equilibrium outcome. On the other hand, the system achieves the best possible product quality if historical quality in a duopoly exceeds this critical value. Thus the initial condition, or history, will decide whether a fragmented duopoly, as modelled in the paper, can reach an efficient equilibrium, or not. Secondly, we also note that large changes in expectations can play a very important role in achieving the efficient equilibrium (a la Krugman, 1991).

The issue of quality variations in markets characterised by asymmetry of information leading to market failure dates back to the classic work of Akerlof (1970). However, unlike the static lemons model, the equilibrium quality in our model gets endogenously determined, which is more representative of certain markets where sellers get to choose the quality of their products. Our model also differs from models of endogenous quality in the industrial organisation literature: these models traditionally rely on reputation as a commitment device to sustain an equilibrium quality (Shapiro, 1983). In contrast, our model explores the question of equilibrium quality when it is difficult, or not economically rational, for sellers to establish credible reputation by investing in a signalling device.

\section{General Cost Function and Disappearance of the Trap}

In this section we abstain away from the special condition in equation (1c) that we introduced for simplifying calculations. We now retain the general functional form of $h(K)$ and posit usual restrictions. Assuming a symmetric equilibrium we set $\mathrm{K}_{\mathrm{i}}=\mathrm{K}_{\mathrm{j}}=\mathrm{K}$ and the profit function of duopolists is now given as:

$$
\Pi_{\mathrm{i}}=\Pi_{\mathrm{j}}=\left[\left(\mathrm{P}-\mathrm{C}_{0}-\mathrm{h}(\mathrm{K})\left(\mathrm{K}-\mathrm{K}^{*}\right)\right] / 2-\mathrm{L}\right.
$$

The first order condition is given by:

$$
\mathrm{K}=\left[\mathrm{h}^{\prime}(\mathrm{K}) \mathrm{K}^{*}-\mathrm{h}(\mathrm{K}) /\left[\mathrm{h}^{\prime}(\mathrm{K})\right]=\psi(\mathrm{K})\right.
$$

Where $h^{\prime}(K=d h(K) / d K$. The equilibrium schedule is as follows:

$$
\mathrm{K}=\psi(\mathrm{K})
$$

The slope of the equilibrium schedule is given as

$$
\psi^{\prime}(\mathrm{K})=\left[\mathrm{h}^{\prime \prime}(\mathrm{K}) \mathrm{h}(\mathrm{K})\right] /-\left[\left(\mathrm{h}^{\prime}(\mathrm{K})\right)^{2}\right]-1
$$

From equation (4c) the following observations are in order:

Observation 2: For $\mathrm{h}^{\prime \prime}(\mathrm{K})=0, \psi^{\prime}(\mathrm{K})<0$. There exists a unique and symmetric Nash equilibrium product quality $\mathrm{K}^{1}$ if $h^{\prime}(0)>0$ since we know by construction $h(0)=0$ and hence $\psi(0)=K^{*}$ and $\psi^{\prime}(K)=-1$. The equilibrium is depicted in Diagram 2 as $\mathrm{E}$ as the fixed point of the equilibrium schedule $\psi(\mathrm{K})$. The equilibrium is not stable since a momentary departure from the equilibrium will create the well-known cobweb dynamics around the equilibrium without a steady convergence, or divergence to, or away, from the equilibrium, as described in arrows in Diagram 2. Suppose an initial disturbance takes the system from the equilibrium point $\mathrm{E}$ to another point $\mathrm{B}$ on 
the $45^{\circ}$ line OA as in Diagram 2, the dynamic adjustment path from point B can be derived as the cobweb path described as the square with arrows in Diagram 2.

\section{Conclusion}

This paper presents a new model of strategic choice of product quality in a segmented market. By construction, the choice of product quality by a seller depends on the (exogenously given) average product quality in the entire industry and also on the product quality chosen by its rival in the specific market segment they compete. Our model highlights several new results hitherto unknown in the literature on product quality: First, in simple situations, the model establishes, multiple equilibria can arise. As a result, segmented markets can be characterised by significant indeterminacy and endogenous uncertainty about product quality. More importantly, the equilibria can be Pareto ranked. As a result, there is nothing sacrosanct about the choice of an efficient equilibrium. Secondly, the instability of one of the equilibria acts as a trap for sellers to get stuck to a low-level equilibrium quality even when it is profitable for them to choose a better quality product. Thirdly, we find that the selection of the high-quality equilibrium depends upon expectations of agents, initial conditions, or history and also specifics of industrial policy.

The model is further extended to cases in which there exists a unique equilibrium in product quality and mathematical restrictions are imposed to ensure that the unique equilibrium is stable. If these restrictions are violated, the model establishes that the unique equilibrium does not have usual stability properties and momentary departures from the equilibrium can generate cobweb type of dynamics in product quality. The model also establishes that the segmented duopoly does not have a pure-strategy Nash equilibrium under certain conditions. The major contribution of the paper is to highlight that segmented markets can display significant uncertainty since rational actors can fail to achieve an efficient equilibrium, which can have serious consequences for consumers. It is important to stress the need for an external intervention in such markets to improve consumer well-being. In other words, our model portends an important role for policy makers to extricate segmented markets from the quality trap, or from the clutches of pathological equilibria. Without an appropriate policy intervention, segmented markets may have an inability to home in on a desirable equilibrium product quality, which can in turn jeopardise the well-being of myriads of consumers in segmented oligopolies.

\section{References}

Acemoglu, Daron. (2003). 'Why Not A Political Coase Theorem? Social Conflict, Commitment, and Politics', Journal of Comparative Economics, 31: 620-652, doi:10.1016/j.jce.2003.09.003, http://dox.doi.org/10.1016/j.jce.2003.09.003.

Acemoglu, D., S. Johnson, and J. A. Robinson (2001). 'The Colonial Origins of Comparative Development: An Empirical Investigation”, American Economic Review, 91: 1369-1401, doi:10.1016/j.jce.2003.09.003, http://dox.doi.org/10.1016/j.jce.2003.09.003.

Akerlof, G. (1970). 'The Market for Lemons: Qualitative Uncertainty and Market Mechanism', Quarterly Journal of Economics, 84: 488-500, doi:10.2139/ssrn.244582, http://dox.doi.org/10.2139/ssrn.244582.

Anderson, S. et.al. (1992). Discrete Choice Theory of Product Differentiation. Cambridge: MIT Press.

Ben-Porath, E. and M. Kahneman (1996). 'Communication in Repeated Games with Private Monitoring', Journal of Economic Theory, 70: 281-297, doi:10.1006/jeth.1996.0090, http://dox.doi.org/10.1006/jeth.1996.0090.

Berentsen, A and G. Rocheteau, (2004). 'Money and Information', Review of Economic Studies, 71(4): 915-44. doi:10.1111/j.1467-937X.2004.00309.x, http://dox.doi.org/10.1111/j.1467-937X.2004.00309.x

Chamberlin, E. (1933). The Theory of Monopolistic Competition. Cambridge: Harvard University Press.

Djankov, Simeon, Rafael La Porta, Florencio Lopez-de-Silanes, and Andrei Shleifer. (2002). 'The Regulation of Entry', Quarterly Journal of Economics, 117(1):1-37, doi:10.1162/003355302753399436, http://dox.doi.org/10.1162/003355302753399436.

Gatti, Stefano, Stefanie Kleimeier, William L. Megginson, and Alessandro Stefanoni. (2007). 'Arranger Certification in Project Finance', Working paper, Bocconi University,Maastricht University, University of Oklahoma, and Interbanca.

Feenstra, R. and J. Levinsohn. (1995). 'Estimating Markups and Market Conduct with Multidimensional Product Attributes', Review of Economic Studies, 62:19-52, doi:10.2307/2297840, http://dox.doi.org/10.2307/2297840.

Gabszewicz, J. and J. Thisse. (1979). 'Pr Hotelling, H. (1929). Stability in Competition', Economic Journal, 39: 41-57.

Gabszewicz, J. and J. Thisse. (1980). 'Entry (and Exit) in a Differentiated Industry', Journal of Economic Theory, 22: 327-338. Green \& Porter (1984).

Kaldor, N. (1935). 'Market Imperfections and Excess Capacity', Economica, 2: 35-50, doi:10.2307/2549105, http://dox.doi.org/10.2307/2549105. 
Kandori, M. and H. Matsushima (1996?). 'Private Observation and Communication in Implicit Collusion', Review of Economic Studies (?).

Kihlstrom, R. and D. Levhari. (1977). 'Quality, Regulation, Efficiency', Kyklos, 30: 214-234. doi:10.1111/j.1467-6435.1977.tb02007.x,http://dox.doi.org/10.1111/j.1467-6435.1977.tb02007.x.

Kleiman E. and T. Ohir. (1966). 'The Durability of Durable Goods', The Review of Economic Studies, 33: 165-178, doi:10.2307/2974440, http://dox.doi.org/10.2307/2974440.

Krugman, P. (1991). 'History versus Expectations', Quarterly Journal of Economics, 106: 51-67, doi:10.2307/2937950, http://dox.doi.org/ 10.2307/2937950.

Levhari, D. and T. N. Srinivasan. (1969). 'Durability of Consumption Goods: Competition versus Monopoly', American Economic Review, 59: 102-107.

Luce, R. D. (1959). Individual Choice Behaviour. Wiley: New York.

North, D. C. (2005). Understanding the Process of Economic Change, Princeton University Press.

Scaperdas, S. (1996). 'Contest Success Functions', Economic Theory, 7: 283-90, doi:10.1007/s001990050053, http://dox.doi.org/10.1007/s001990050053.

Scherer, F. M. (1990). Industrial Market Structure and Economic Performance, Houghton: New York.

Schmalensee, R. (1992). 'Sunk Costs and Market Structure: A Review Article', Journal of Industrial Economics, 40: 125-134, doi:10.2307/2950504, http://dox.doi.org/10.2307/2950504.

Schmalensee, R. (1985). 'Econometric Diagnosis of Competitive Localization', International Journal of Industrial Organization, 3: 57-70, doi:10.1016/0167-7187(85)90013-X, http://dox.doi.org/10.1016/0167-7187(85)90013-X.

Schmalensee, R. (1979). 'Market Structure, Durability, and Quality: A Selective Survey', Economic Inquiry, 17: 177-96, doi:10.1111/j.1465-7295.1979.tb00307.x, http://dox.doi.org/10.1111/j.1465-7295.1979.tb00307.x.

Shaked, A. and J. Sutton. (1982). 'Relaxing Price Competition Through Product Differentiation', Review of Economic Studies, 49: 1-13, doi:10.2307/2297136, http://dox.doi.org/10.2307/2297136.

Shapiro, C. (1983). 'Premiums to High Quality Products as Returns to Reputations", Quarterly Economic Journal, 98: 659-80, doi:10.2307/1881782, http://dox.doi.org/10.2307/1881782.

Stigler (1964)

Swan, P. (1970). 'Durability of Consumer Goods', American Economic Review, 60: 884-894.

Swan, P. (1971). 'The Durability of Consumer Goods and the Regulation of Monopoly', Bell Journal of Economics, 2: 347-357.

Wolinsky, A. (1983). 'Prices as Signals of Product Quality', Review of Economic Studies, 50: 647-658, doi:10.2307/2297767, http://dox.doi.org/10.2307/2297767.

Diagram 1: Stability of the Fixed Points and the Quality Trap

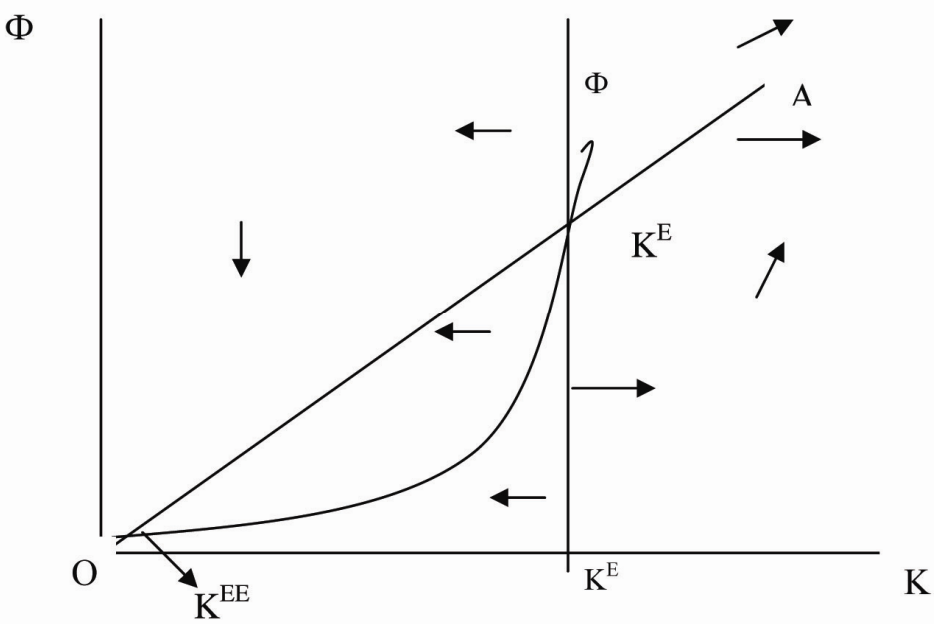

Note: The above diagram depicts the equilibrium schedule (3d). It represents $\mathrm{K}$ along the horizontal axis and $\Phi$ along the vertical axis and the schedule $\Phi$ is the concave up curve. $\mathrm{OA}$ is the $45^{\circ}$ Line and $\mathrm{K}^{\mathrm{EE}}$ and $\mathrm{K}^{\mathrm{E}}$ are the two fixed points, or equilibrium product qualities. Note that $\mathrm{K}^{\mathrm{EE}}$ is stable and $\mathrm{K}^{\mathrm{E}}$ is unstable. The vertical line at $\mathrm{K}^{\mathrm{E}}$ is the separatrix. 
Diagram 2: Unique Equilibrium with Cobweb Dynamics

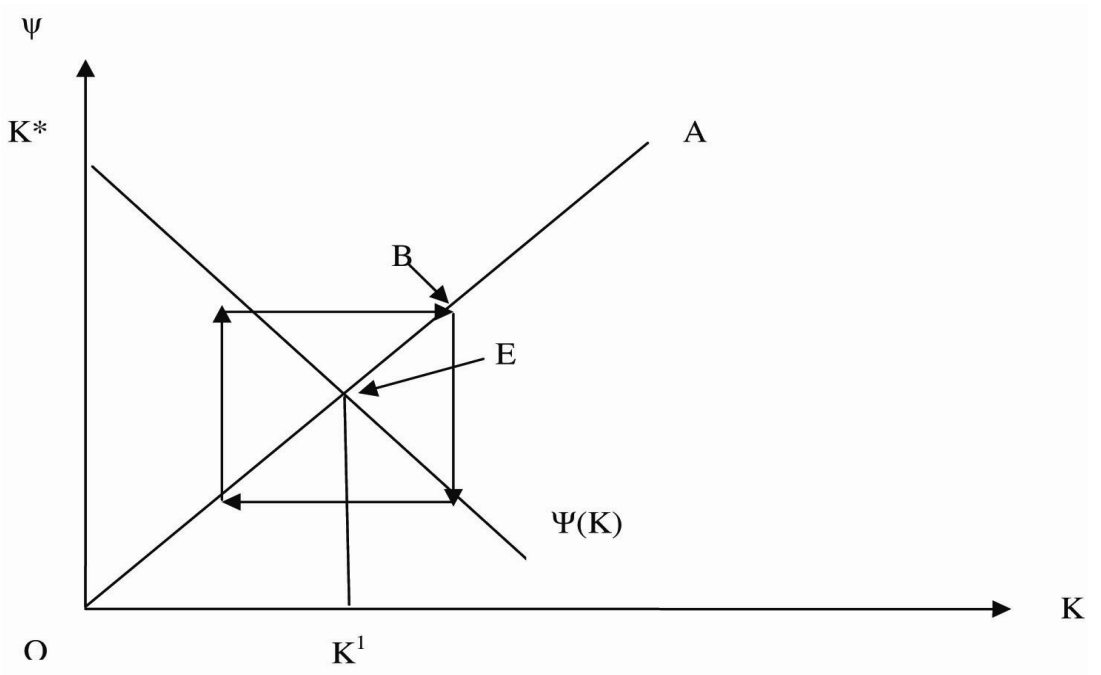

Observation 3: For $\mathrm{h}^{\prime \prime}(\mathrm{K})>0$ and $\left[\mathrm{h}^{\prime \prime}(\mathrm{K}) \mathrm{h}(\mathrm{K})\right] /-\left[\left(\mathrm{h}^{\prime}(\mathrm{K})\right)^{2}\right]<2$ there exists a unique and stable equilibrium $\mathrm{E}^{2}$. In Diagram 3 the equilibrium is shown as the fixed point of $\psi(K)$ and the inequality, $\left[h^{\prime \prime}(K) h(K)\right] /-\left[\left(h^{\prime}(K)\right)^{2}\right]<2$, and $h^{\prime \prime}(K)>0$, ensures that $\psi(K)$ is concave starting at $K^{*}>0$.

Diagram 3: A Unique and Stable Quality Equilibrium

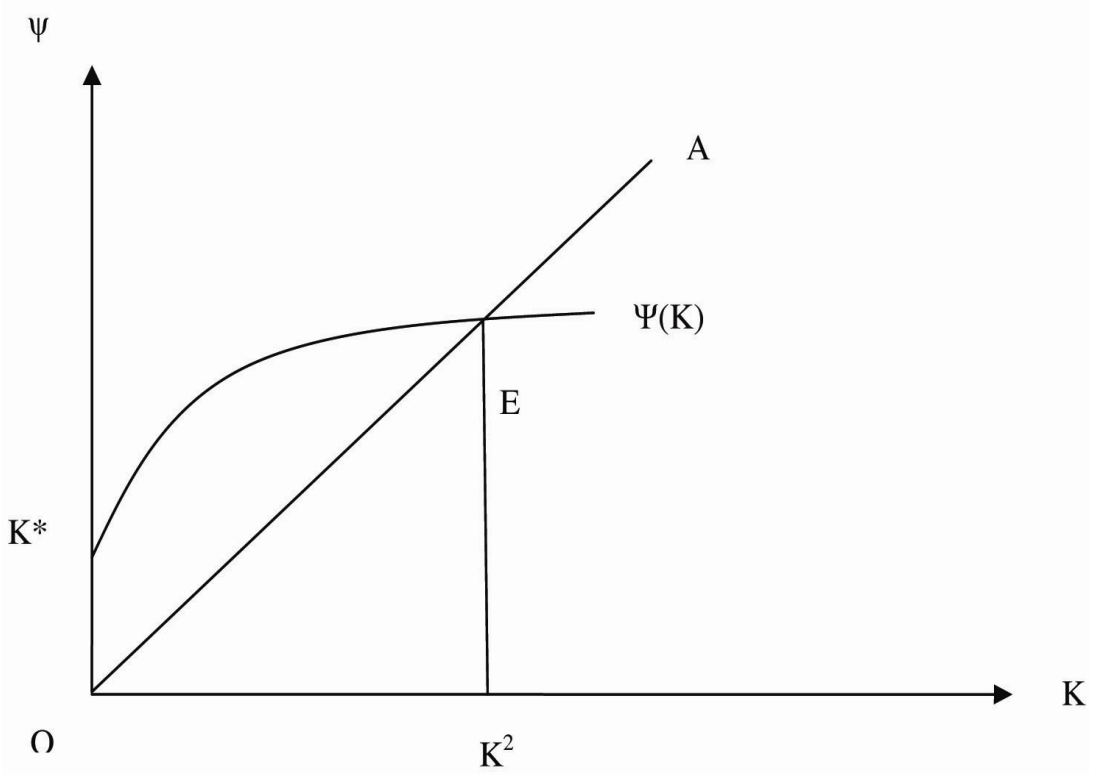

Observation 4: If $\left[h^{\prime \prime}(\mathrm{K}) \mathrm{h}(\mathrm{K})\right] /-\left[\left(\mathrm{h}^{\prime}(\mathrm{K})\right)^{2}\right]>2$, and $\mathrm{h}^{\prime \prime}(\mathrm{K})>0$; there does not exist any equilibrium since $\psi(0)=\mathrm{K}^{*}$. This is so since the function $\psi(K)$ is concave upward if $\left[h^{\prime \prime}(K) h(K)\right] /-\left[\left(h^{\prime}(K)\right)^{2}\right]>2$. For $K=0, \psi(0)=K^{*}>0$ and since $\psi^{\prime \prime}(\mathrm{K})>0$, there does not exist any fixed point to equation (4b). In other words, $\psi(\mathrm{K})$ and the $45^{\circ}$ line do not have an intersection under these conditions. 